\title{
Cardiorespiratory Fitness in Women with and without Lymphedema following Breast Cancer Treatment
}

\author{
Betty Smoot ${ }^{1}$, Morgan Johnson ${ }^{1}$, John Duda $J^{2}$, Joanne Krasnoff ${ }^{3} \&$ Marylin Dodd $^{4}$ \\ ${ }^{1}$ Department of Physical Therapy and Rehabilitation Science, University of California, San Francisco, CA, USA \\ ${ }^{2}$ Clinical and Translational Science Institute Clinical Research Center, University of California, San Francisco, \\ CA, USA \\ ${ }^{3}$ Clinical Research Center, University of Miami Miller School of Medicine, Miami, USA \\ ${ }^{4}$ Department of Physiological Nursing, University of California, San Francisco, CA, USA \\ Correspondence: Betty Smoot, Department of Physical Therapy and Rehabilitation Science, University of \\ California, San Francisco, CA, USA
}

\author{
Received: February 19, 2012 Accepted: March 6, 2012 Published: May 1, 2012 \\ doi:10.5539/cco.v1n1p21 URL: http://dx.doi.org/10.5539/cco.v1n1p21
}

This research was supported by a grant from the National Institute of Nursing Research (NIH 1R21 NR0101282U) and by NIH/NCRR UCSF-CTSI Grant Number UL1 RR024131. Its contents are solely the responsibility of the author and do not necessarily represent the official views of the National Institutes of Health

\begin{abstract}
Following breast cancer (BC) treatment, many women develop impairments that may impact cardiorespiratory (CR) fitness. The aims of this study were to 1) evaluate CR fitness in women following BC treatment, 2) evaluate differences in CR fitness in those with and without breast cancer-related lymphedema (BCRL) and compare these to age-matched norms, and 3) evaluate the contribution of predictor variables to CR fitness. 136 women post-BC treatment completed testing: 67 with $\mathrm{BCRL}$, and 69 without. $\mathrm{VO}_{2}$ peak was lower in participants compared to published healthy age-matched norms. $\mathrm{VO}_{2}$ peak was statistically significantly lower in women withBCRL. Age, BMI, meeting recommended exercise criteria, and DASH scores explained $50 \%$ of the variance in $\mathrm{VO}_{2}$ peak $(\mathrm{R}=0.708, \mathrm{p}<0.001)$. Following $\mathrm{BC}$ treatment $\mathrm{CR}$ fitness may be impaired, more-so in women with BCRL. This should be considered when providing rehabilitation for women following BC treatment as cardiorespiratory fitness has linked to improved health outcomes and survivorship.
\end{abstract}

Keywords: lymphedema, breast cancer, survivorship, cardiorespiratory fitness

\section{Introduction}

Breast cancer survival rates and life expectancy continue to increase due to improved diagnosis and treatment. However, treatment sideeffects are common (Cheville, Troxel, Basford, \& Kornblith, 2008). Cancer treatments impact the musculoskeletal, lymphatic, cardiovascular, and respiratory systems. Recognizing treatment complications allows for timely interventions that can reduce impairments such as pain, loss of upper extremity mobility, breast cancer-related lymphedema (BCRL), and deconditioning.

Persistent sequelae of breast cancer treatment include pain, impaired use of the ipsilateral upper extremity, and lymphedema (Rietman et al., 2003; Smoot et al., 2010). These sequelae may affect the ability to participate in physical activity. Women with BCRL experience more pain, greater limitations in arm function, greater restrictions in activity, and poorer quality of life than women without BCRL (Dawes, Meterissian, Goldberg, \& Mayo, 2008; W. Kwan et al., 2002; Ridner, 2005; Smoot et al., 2010). Additionally, treatments for breast cancer may directly affect cardiovascular and pulmonary function. Lung and/or cardiac toxicity may be seen following radiation therapy (Calitchi et al., 2001; Fehlauer et al., 2003; Gillette, Mahler, Powers, Gillette, \& Vujaskovic, 1995; Shapiro \& Recht, 2001). Dorr et al. (2005) observed clinical symptoms of pneumonitis in 5.5\% of subjects, and late radiologic lung changes in $22.1 \%$ of subjects who received breast irradiation. Certain chemotherapeutic drugs directly damage the myocardium, resulting in cardiomyopathy. Damage to the myocardium may lead to reduced left ventricular ejection fraction $(<50 \%)$ and/or arrhythmias (Jones et al., 2007). 
While these adjuvant therapies may directly result in cardiovascular complications, decline in cardiovascular function may also be the result of a decline in physical activity. Participation in regular physical activity may prove challenging for women during and after treatment for breast cancer due in part to side effects and persistent complications of treatment. Irwin et al. (2003) reported an average decline in physical activity of 2 hours per week in women from time of breast cancer diagnosis up to one year after. Women with higher BMI at time of diagnosis, and those who received adjuvant therapy reported greater declines in physical activity. These finding are supported by the results of Kwan et al. (2011), from a large prospective study of 1,696 women diagnosed with invasive breast cancer.

The link between physical activity (a behavior) and cardiorespiratory fitness (an attribute) is well established. While physical activity is often measured through self-report, cardiorespiratory (CR) fitness is assessed through objective measures such as exercise capacity measured by peak oxygen uptake $\left(\mathrm{VO}_{2}\right.$ peak). Both physical activity and cardiorespiratory fitness have been linked to health outcomes in healthy adults (Lakoski et al., 2011; Sassen, Kok, Schaalma, Kiers, \& Vanhees, 2010). The relationship between physical activity and CR fitness has been demonstrated in breast cancer survivors as well. Taylor et al. (2010) reported a statistically significant positive correlation between physical activity and CR fitness in a cross-sectional study evaluating CR fitness, physical activity, and quality of life in breast cancer survivors. Not surprisingly, age and BMI were also found to correlate with CR fitness. There is ample evidence to support that increasing physical activity in cancer survivors results in increased CR fitness (McMillan \& Newhouse, 2011; McNeely et al., 2006). Higher fitness categories show lower mortality rates for cancer and cardiovascular disease. It is essential to determine if women are at particular risk for greater reductions in CR fitness following breast cancer treatment, and which subgroups may be at even greater risk, so that we may intervene early to minimize the consequence of poor cardiorespiratory fitness.

It is reasonable to suspect that breast cancer survivors with BCRL, who have greater limitations in upper extremity mobility, more pain, and higher BMI(Smoot et al., 2010) are less physically active and have greater reductions in CR fitness compared to women without BCRL. However, differences in CR fitness between women with BCRL and those without have not been reported. Therefore, the aims of this study were to 1) objectively evaluate $\mathrm{CR}$ fitness in women following $\mathrm{BC}$ treatment, 2) evaluate differences in CR fitness in those with and without BCRL and compare to age-matched norms, and 3) to evaluate the contribution of predictor variables to $\mathrm{CR}$ fitness $\left(\mathrm{VO}_{2}\right.$ peak).

\section{Methods}

\subsection{Participants}

One hundred and forty-five female breast cancer survivors were recruited from the National Lymphedema Network website, San Francisco Bay area hospitals, San Francisco Bay area breast cancer or lymphedema support groups, and breast cancer conferences. Participants were excluded for bilateral breast cancer, current upper extremity infection, pre-existing lymphedema, recurrence of breast cancer, or if they were unable to read and understand English. Patients were excluded if they had orthopedic limitations, psychiatric or neurological disorders that precluded exercise testing, and/or had any absolute contraindications to exercise testing as established by the American College of Cardiology/American Heart Association or the American College of Sports Medicine (American College of Sports Medicine, 2000). Written informed consent was obtained for all participants. All participants attended a single evaluation session, during which all testing occurred. All testing was performed in the UCSF CTSI Clinical Research Center according to procedures approved by the Committee on Human Research at the University of California at San Francisco (UCSF). The study was approved by the UCSF Committee on Human Research and the Clinical and Translational Science (CTSI) Clinical Research Center Advisory Committee.

\subsection{Procedures}

\subsubsection{Health Status}

A demographic questionnaire was used to collect information on age, health, income, ethnicity, menopausal status, performance and activity status, occupation, and health status. Information regarding comorbidities was obtained. Twelve comorbidities were included in the comorbidity listing: heart disease, high blood pressure, lung disease, diabetes, stomach disease or ulcer, urinary tract disorders/kidney disease, liver or gallbladder disease, anemia or other blood disease, depression, osteoarthritis, rheumatoid arthritis, and back pain/problems. 


\subsubsection{Upper Extremity Disability}

All participants completed the Disabilities of Arm, Shoulder, and Hand (DASH). The DASH is a 30-item, self-report questionnaire which measures physical function and symptoms on a 1-5 response scale, in people with musculoskeletal disorders of the upper extremity (Gummesson, Atroshi, \& Ekdahl, 2003). Scores are typically converted to 0 to 100 with higher scores reflective of greater disability. Test-retest reliability for the DASH has been reported as $r=0.96$ (Beaton et al., 2001).

\subsubsection{Shoulder Range of Motion and Strength}

A goniometer was used to measure the range of motion (ROM) of shoulder flexion, abduction, external rotation, and internal rotation using standardized procedures reported by Norkin(Norkin \& White, 2003). The MicroFET2 dynamometer (Hoggan MicroFET2 Muscle Tester, Model 7477, Pro Med Products, Atlanta, GA) was used to measure shoulder abduction strength. Participants were instructed to perform with maximal exertion. Three trials were performed, and a mean was calculated.

\subsubsection{Upper Extremity Limb Volume}

Circumferential assessment and multi-frequency bioimpedance were employed to objectively assess upper extremity limb volume. A flexible tape measure was used to measure circumference of each upper extremity at the ulnar styloid, designated as " 0 " centimeters, and at 10 centimeter intervals proximal to " 0 " to a maximum of 40 centimeters. Volume was calculated from circumference measures using the formula for volume of a truncated cone, $V=1 / 12 \Pi \Sigma h\left(C_{1}^{2}+C_{1} C_{2}+C_{2}^{2}\right)$, where $h$ is the length of each measured segment and $\mathrm{C}$ is the circumference at each end of that segment (Sander, Hajer, Hemenway, \& Miller, 2002). The Impedimed measurement system (SBF7, Garden City, Australia) was used to measure upper extremity impedance to an alternating current which provided information about fluid distribution in the upper extremities. Electrodes were placed on the dorsum of the hands, wrists, feet and ankles. The participants were instructed to consume no food or fluids within one hour, to avoid vigorous exercise within 2 hours and to avoid excessive alcohol intake for the 12 hours, prior to the study visit. During testing, instructions were given to lie supine for 10 minutes with no pillows, arms at sides and lower extremities flat and slightly abducted.

\subsubsection{Cardiorespiratory Fitness}

Cardiorespiratory fitness was evaluated using symptom-limited treadmill testing. A branching treadmill protocol was used. The participant began testing by walking on the treadmill at a speed which was determined to be comfortable to them (American College of Sports Medicine, 2000). Exercise intensity was then adjusted by grade (elevation) every two minutes to achieve approximately a 1-2 metabolic equivalent (MET) increment between stages ( $3.5 \mathrm{ml}$ oxygen per $\mathrm{Kg}$ body weight per minute - estimated resting oxygen consumption). Exercise intensitywas increased until the subject was unable to continue (volitional fatigue) or until there was indication to discontinue the test (i.e. electrocardiographic changes, inappropriate blood pressure response) (American College of Sports Medicine, 2000). A 12-lead electrocardiogram was monitored continuously throughout the test and blood pressure was auscultated at every stage. Ratings of perceived exertion (RPE) were evaluated at the end of each stage (every 2 minutes) (Myers \& Froelicher, 1993). Oxygen consumption was determined using an open-circuit spirometry system (Quinton metabolic cart, Bothell, WA), which was calibrated against known gases before each test. Respiratory gases were analyzed for volume and fractions of oxygen and carbon dioxide, and $\mathrm{VO}_{2}$ was calculated. Peak $\mathrm{VO}_{2}$ is expressed in terms relative to body weight (milliliters of oxygen per kilogram of body weight per minute).

Maximal oxygen consumption $\left(\mathrm{VO}_{2}\right.$ peak) was defined as the highest level of oxygen consumption achieved during the test and was expressed in $\mathrm{ml}$ oxygen per Kg body weight per minute (ml.kg-1.min-1). Hemodynamic responses to testing were evaluated at peak exercise levels (i.e., maximal heart rate, maximal blood pressure, maximal RPE).

\subsection{Data Analysis}

Sample size estimate of 120 participants was based on an alpha of 0.05 , power of 0.80 , and an estimated correlation coefficient of 0.25 for regression analysis. Descriptive statistics (means, standard deviations) were calculated for all continuous variables and frequencies were generated for the non-continuous variables. T-tests were used to compare the BCRL group to the participants without BCRL. Mann-Whitney ranked sum analysis was used for non-normally distributed interval data. Chi-square was used to assess significance of differences in proportions for nominal and categorical variables. Repeated measures analysis of variance was used to determine between and within groups differences where appropriate. Multiple linear regression analysis was used to evaluate the contribution of predictor variables to the variance in the outcome measure $\left(\mathrm{VO}_{2}\right.$ peak). Statistical significance was 
set at $\mathrm{p}<0.05$. Statistical analyses were performed using SPSS statistical software (version 18, SPSS Inc, Chicago, IL).

\section{Results}

\subsection{Participant Characteristics and Health Status}

On the day of testing, one woman was excluded from bioimpedance and treadmill testing due to having a pacemaker. Six others declined treadmill testing on the day of the visit due to: knee pain (1), ankle or foot injury (3), anxiety associated with the test (1), and language barrier (1). Another two women were unable to complete the treadmill test due to inability to tolerate the mouthpiece (1) or knee pain (1). One hundred and thirty-six women completed fitness testing.

Table 1. Characteristics of study participants (means and standard deviations, or frequency)

\begin{tabular}{|c|c|c|c|c|c|}
\hline Characteristics & $\begin{array}{c}\text { All } \\
\text { participants } \\
n=136\end{array}$ & $\begin{array}{c}\text { Without } \\
\text { BCRL } \\
n=69\end{array}$ & $\begin{array}{l}\text { With BCRL } \\
\qquad \mathbf{n}=67\end{array}$ & $\begin{array}{c}\text { Difference in } \\
\text { means (95\% } \\
\text { confidence } \\
\text { interval) }\end{array}$ & Sig.(p) \\
\hline Age (years) & $56.38(9.47)$ & $55.16(8.87)$ & $57.69(9.98)$ & $2.26(5.44,0.93)$ & $0.163^{\mathrm{a}}$ \\
\hline Years of education & $16.62(2.70)$ & $17.06(2.48)$ & $16.16(2.86)$ & $0.90(-3.04,0.412)$ & $0.140^{\mathrm{a}}$ \\
\hline \multicolumn{6}{|l|}{ Marital status: } \\
\hline Married/Partnered & 88 & 50 & 38 & & \multirow{6}{*}{0.068} \\
\hline Widowed & 7 & 0 & 7 & & \\
\hline Divorced & 15 & 9 & 6 & & \\
\hline Separated & 2 & 1 & 1 & & \\
\hline Never married & 18 & 7 & 11 & & \\
\hline Living with significant other & 3 & 2 & 1 & & \\
\hline \multicolumn{6}{|l|}{ Yearly gross household income: } \\
\hline$<19,999$ & 4 & 0 & 4 & & \multirow{6}{*}{$0.014^{b}$} \\
\hline $20,000-39,000$ & 6 & 1 & 5 & & \\
\hline $40,000-59,000$ & 13 & 2 & 11 & & \\
\hline $60,000-79,000$ & 20 & 9 & 11 & & \\
\hline $80,000-99,000$ & 14 & 9 & 5 & & \\
\hline$>100,000$ & 63 & 42 & 21 & & \\
\hline Number of women post menopause & 114 & 58 & 56 & & 0.541 \\
\hline Years since breast cancer diagnosis & $6.18(5.30)$ & $4.90(4.08)$ & $7.56(6.09)$ & $2.66(-4.42,-0.89)$ & $0.004^{\mathrm{a}}$ \\
\hline \multicolumn{6}{|l|}{ Number of women who had: } \\
\hline Breast conserving surgery & 75 & 39 & 36 & & \multirow{2}{*}{$0.980^{\mathrm{b}}$} \\
\hline Mastectomy & 58 & 30 & 28 & & \\
\hline Number of nodes removed & $10.68(7.16)$ & $8.62(6.47)$ & $12.90(7.26)$ & $4.29(-6.66,-1.91)$ & $<0.001^{\mathrm{a}}$ \\
\hline $\begin{array}{l}\text { Number of women who received } \\
\text { radiation therapy }\end{array}$ & 98 & 48 & 50 & & $0.263^{\mathrm{b}}$ \\
\hline $\begin{array}{l}\text { Number of women who received } \\
\text { chemotherapy }\end{array}$ & 91 & 46 & 45 & & $0.650^{\mathrm{b}}$ \\
\hline
\end{tabular}

BCRL: Breast-cancer related lymphedema

${ }^{\mathrm{a}}$ independent $\mathrm{t}$-tests for differences in means ${ }^{\mathrm{b}}$ Chi square 
Participants were dichotomized into two groups: women with previously diagnosed BCRL $(n=67)$, and women without $(n=69)$. Participant characteristics are presented in Table 1 . Statistically significant differences were found between groups for annual yearly income, time since breast cancer diagnosis, and number of nodes removed. Of the nine women who did not complete treadmill testing, seven had been previously diagnosed with lymphedema. No statistically significant differences were found in any outcomes between the women who did and did not complete fitness testing.

No statistically significant differences were found between groups for the health related questions (types and numbers of co-morbidities, weight change, BMI, smoking history, depression, medication use, and meeting recommended exercise criteria).

\subsection{Upper Extremity Disability}

DASH scores were non-normally distributed. For the entire group the median was 8.00 with a range of 0 to 63 on the 0 to 100 scale (Table 2). The median for the women with BCRL was 13 (range 0-63) and for the women without BCRL the median was 4.00 (range 0-58). Though both groups' scores were low, the difference did reach statistical significance. A higher DASH score is indicative of relatively greater limitation.

\subsection{Shoulder Range of Motion and Strength}

While there were no differences in shoulder abduction strength between sides or between groups, there were differences in shoulder ROM (Table 2). The women with lymphedema demonstrated less shoulder ROM bilaterally than the women without lymphedema, particularly on the affected side. Analysis of variance revealed statistically significant between and within groups differences $(p<0.05)$.

Table 2. Comparison of outcomes between groups. Means and standard deviations for all except DASH presented as median and range

\begin{tabular}{|c|c|c|c|c|c|}
\hline & $\begin{array}{c}\text { All } \\
\text { participants } \\
n=136\end{array}$ & $\begin{array}{l}\text { Without } \\
\text { BCRL } \\
\mathbf{n}=69\end{array}$ & $\begin{array}{l}\text { With } \\
\text { BCRL } \\
\mathbf{n}=67\end{array}$ & $\begin{array}{c}\text { Differences } \\
\text { between groups } \\
\text { Mean }(95 \% \mathrm{CI})\end{array}$ & Sig.(p) \\
\hline $\operatorname{BMI}\left(\mathrm{kg} / \mathrm{m}^{2)}\right.$ & $26.10(5.05)$ & $25.47(4.69)$ & $\begin{array}{c}26.78(5.37 \\
)\end{array}$ & $\begin{array}{l}1.31(-3.04 \\
0.413)\end{array}$ & $0.135^{\mathrm{a}}$ \\
\hline $\begin{array}{l}\text { Volume difference between } \\
\text { arms (ml) }\end{array}$ & $\begin{array}{l}91.83(212.2 \\
3)\end{array}$ & $-9.15(72.83)$ & $\begin{array}{c}200.69(255 \\
.82)\end{array}$ & $\begin{array}{c}209.84(273.35 \\
146.33)\end{array}$ & $<0.001^{\mathrm{a}}$ \\
\hline $\begin{array}{l}\text { Bioimpedance resistance } \\
\text { ratio(unaffected limb/affected } \\
\text { limb) }\end{array}$ & $1.05(0.13)$ & $0.99(0.04)$ & $1.12(0.16)$ & $0.13(0.17,0.09)$ & $<0.001^{\mathrm{a}}$ \\
\hline $\begin{array}{l}\text { Shoulder abduction range of } \\
\text { motion affected side (degrees) }\end{array}$ & $\begin{array}{c}148.03(28.1 \\
1)\end{array}$ & $\begin{array}{c}154.10(25.12 \\
)\end{array}$ & $\begin{array}{c}141.48(29 \\
80)\end{array}$ & $\begin{array}{l}12.62(3.18 \\
22.06)\end{array}$ & $0.009^{\mathrm{a}}$ \\
\hline $\begin{array}{l}\text { Shoulder abduction ROM } \\
\text { unaffected side (degrees) }\end{array}$ & $160.4(19.20)$ & $\begin{array}{c}162.61(18.32 \\
)\end{array}$ & $\begin{array}{l}158.14(20 . \\
00)\end{array}$ & $\begin{array}{c}4.47(-2.10 \\
11.04)\end{array}$ & $0.181^{\mathrm{a}}$ \\
\hline $\mathrm{VO}_{2} \operatorname{Peak}(\mathrm{ml} / \mathrm{kg} / \mathrm{min})$ & $25.48(6.04)$ & $26.78(6.58)$ & $\begin{array}{c}24.13(5.15 \\
)\end{array}$ & $\begin{array}{l}2.65(0.644, \\
4.66)\end{array}$ & $0.01^{\mathrm{a}}$ \\
\hline DASH (scale 0-100) & $8(0-63)$ & $4(0-58)$ & $13(0-63)$ & & $<0.001^{\mathrm{b}}$ \\
\hline
\end{tabular}

BCRL: Breast-cancer related lymphedema

DASH: Disability of arm, hand, and shoulderBMI: Body mass index

CI: confidence interval

ROM: range of motion

aindependent $\mathrm{t}$-tests for differences in means

${ }^{\mathrm{b}}$ Mann-Whitney test for non-normally distributed data

\subsection{Upper Extremity Limb Volume}

Differences in limb volume (affected limb - unaffected limb) were determined, as were bioimpedance resistance ratios (unaffected limb/affected limb) and are presented in Table 2. Differences between groups are large (for each: effect size $=1.12,95 \%$ confidence interval $0.76,1.48)$ and statistically significant $(p<0.001)$. Statistically 
significant differences in volume calculated from circumference were found forthe 40-49, 50-59, and 60-69 year old age subgroups (Table 3).

Table 3.Volume calculated from circumference, by age group

\begin{tabular}{cccc}
\hline \multicolumn{3}{c}{$\begin{array}{c}\text { Interlimb volume differences (milliliters) } \\
\text { mean (standard deviation) }\end{array}$} \\
\hline Age (years) & $\begin{array}{c}\text { Without BCRL } \\
\mathbf{( n = 6 9 )}\end{array}$ & $\begin{array}{c}\text { With BCRL } \\
(\mathbf{n}=\mathbf{6 7})\end{array}$ & $\begin{array}{c}\text { Sig. } \\
(\boldsymbol{p})\end{array}$ \\
\hline $30-39$ & $47.7(58.49)$ & $109.15(\mathrm{n}=1)$ & \\
$40-49$ & $-6.10(82.97)$ & $151.38(197.06)$ & 0.022 \\
$50-59$ & $-15.23(60.02)$ & $201.27(297.46)$ & $<0.001$ \\
$60-69$ & $-14.60(76.58)$ & $171.69(223.88)$ & 0.002 \\
$70+$ & $43.81(208.22)$ & $315.98(267.94)$ & 0.210 \\
\hline
\end{tabular}

BCRL: Breast-cancer related lymphedema

\subsection{Cardiorespiratory Fitness}

$\mathrm{VO}_{2}$ peak for the entire sample was $25.48 \mathrm{ml} / \mathrm{kg} / \mathrm{min}$ (6.04), in the 30th percentile for published healthy female age-matched controls. Between groups comparison demonstrated statistically significant differences between the women with and without BCRL. $\mathrm{VO}_{2}$ peak for the BCRL group was $24.13 \mathrm{ml} / \mathrm{kg} / \mathrm{min}$ (5.15) and for the non-BCRL group $26.78 \mathrm{ml} / \mathrm{kg} / \mathrm{min}$ (6.57) (Table 2). The difference of $2.65 \mathrm{ml} / \mathrm{kg} / \mathrm{min}$ was statistically significant $(95 \%$ CI $0.64,4.66)$. Qualitative comparisons to published age-matched normative data are presented in Figure 1. Comparisons of $\mathrm{VO}_{2}$ peak by age subgroup are presented in Table 4.

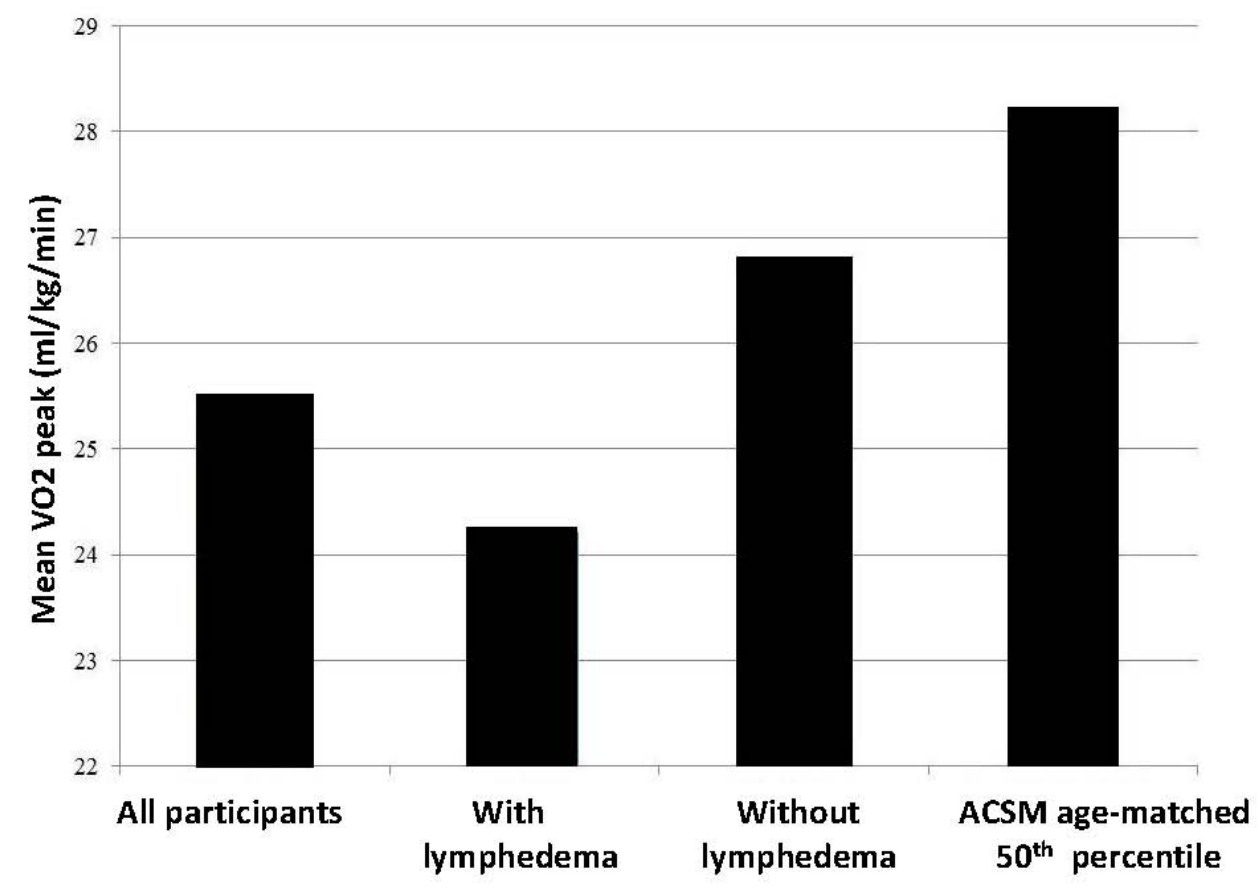

Figure 1. Comparison of mean VO2 peak for participants to American College of Sports Medicine age-matched 50th percentile for healthy women 
Table $4 . \mathrm{VO}_{2}$ peak, by age group

\begin{tabular}{|c|c|c|c|c|c|c|c|c|c|c|c|c|c|}
\hline \multirow[b]{2}{*}{$\begin{array}{l}\text { Age } \\
\text { years }\end{array}$} & \multicolumn{4}{|c|}{$\begin{array}{c}\mathrm{VO}_{2} \text { peak } \mathrm{ml} / \mathrm{kg} / \mathrm{min} \\
\text { mean (standard deviation) }\end{array}$} & \multicolumn{9}{|c|}{ Normative values for VO2 max and associated percentiles* } \\
\hline & $\begin{array}{c}\text { All } \\
N=136\end{array}$ & $\begin{array}{l}\text { Without } \\
\text { BCRL } \\
\text { N = 69 }\end{array}$ & $\begin{array}{l}\text { With } \\
\text { BCRL } \\
N=67\end{array}$ & $\begin{array}{l}\text { Sig. } \\
(p)\end{array}$ & $\begin{array}{l}\text { Ageye } \\
\text { ars }\end{array}$ & 80th & 70th & 60th & 50th & 40th & 30th & 20th & 10th \\
\hline $30-39$ & $\begin{array}{l}29.71 \\
(7.06)\end{array}$ & $\begin{array}{c}26.28 \\
(2.06) \mathrm{n}= \\
3\end{array}$ & $\begin{array}{c}40.00 n= \\
1\end{array}$ & & $30-39$ & 38.6 & 36.7 & 34.6 & 33.8 & 32.3 & 30.5 & 28.7 & 26.5 \\
\hline $40-49$ & $\begin{array}{l}28.93 \\
(7.08)\end{array}$ & $\begin{array}{c}32.32 \\
(7.82) \mathrm{n}= \\
11\end{array}$ & $\begin{array}{c}25.70 \\
(4.41) \mathrm{n} \\
=15\end{array}$ & 0.011 & $40-49$ & 36.3 & 33.8 & 32.3 & 30.9 & 29.5 & 28.3 & 26.5 & 25.1 \\
\hline $50-59$ & $\begin{array}{l}25.62 \\
(5.60)\end{array}$ & $\begin{array}{c}26.64 \\
(5.68) \mathrm{n}= \\
34\end{array}$ & $\begin{array}{l}24.29 \\
(5.31) \mathrm{n} \\
=26\end{array}$ & 0.108 & $50-59$ & 32.3 & 30.9 & 29.4 & 28.2 & 26.9 & 25.5 & 24.3 & 22.3 \\
\hline $60-69$ & $\begin{array}{l}23.70 \\
(5.05)\end{array}$ & $\begin{array}{c}24.17 \\
(5.29) \mathrm{n}= \\
19\end{array}$ & $\begin{array}{c}23.12 \\
(4.85) \mathrm{n} \\
=15\end{array}$ & 0.555 & \multirow{2}{*}{$>60$} & \multirow{2}{*}{31.2} & \multirow{2}{*}{29.4} & \multirow{2}{*}{27.2} & \multirow{2}{*}{25.8} & \multirow{2}{*}{24.5} & \multirow{2}{*}{23.8} & \multirow{2}{*}{22.8} & \multirow{2}{*}{20.8} \\
\hline 70-89 & $\begin{array}{l}20.88 \\
(2.95)\end{array}$ & $\begin{array}{c}18.78 \\
(4.77) \mathrm{n}= \\
2\end{array}$ & $\begin{array}{c}21.30 \\
(2.62) \mathrm{n} \\
=10\end{array}$ & 0.289 & & & & & & & & & \\
\hline
\end{tabular}

BCRL: Breast-cancer related lymphedema

* American College of Sports Medicine ACSM's Guidelines for Exercise Testing and Prescription, $6^{\text {th }}$ Edition.

Williams and Wilkins, 2000

$\mathrm{VO}_{2}$ peak was higher in the one woman with previously-diagnosed lymphedema in the 30-39 year age range. This participant exceeded the ACSM exercise guidelines, exercising more than 5 times per week and for more than 45 minutes each session.Her interlimb volume difference was almost identical to that of one of the non-lymphedema participants in the same age range ( $109.15 \mathrm{ml}$ versus $109.18 \mathrm{ml})$. In the $70-89$ year range, differences in $\mathrm{VO}_{2}$ peak did not reach statistical significance, nor did differences in interlimb volume between the women with and without lymphedema.

\subsection{Regression Analysis}

Correlations between potential predictors and $\mathrm{VO}_{2}$ peak were performed in thematic sets to determine the variables to include in the regression analysis (Table 5). Thematic sets included: 1) known contributors to aerobic capacity, 2) participant characteristics, 3) outcomes related to measurement of lymphedema, 4) signs and symptoms and 5) breast cancer treatments. Variables were retained for regression as potential predictor variables if there was a correlation of $\mathrm{r}>.20$ with a significance level of $p<0.01$ for the correlation with $\mathrm{VO}_{2}$ peak. $\mathrm{VO}_{2}$ peak was then regressed on the variables retained. The predictors in the model that failed to satisfy alpha $<0.1$ criterion were identified and progressively removed from the model, beginning with the variable with the highest $p$ value. Age, BMI, affected shoulder abduction ROM, meeting recommended exercise criteria, DASH score and prior BCRL treatment were included in the original regression model. Age $(p<0.001)$, BMI $(p<0.001)$, meeting recommended exercise criteria $(\mathrm{p}=.001)$, and DASH score $(\mathrm{p}=.003)$ were found to significantly contribute to the variance in $\mathrm{VO}_{2}$ peak $\left(\mathrm{R}=0.708, \mathrm{R}^{2}=.501, \mathrm{~F}=30.4, \mathrm{p}<0.001\right)$ (Table 6). 
Table 5. Thematic sets for correlations

\begin{tabular}{|c|c|}
\hline \multirow{3}{*}{ Contributors to $\mathrm{VO}_{2}$} & Exercise Criteria Met \\
\hline & Age \\
\hline & BMI \\
\hline \multirow{5}{*}{ Treatment } & Chemotherapy \\
\hline & Radiation \\
\hline & Number of Lymph Nodes Removed \\
\hline & Hormone Therapy \\
\hline & Currently Taking Medication \\
\hline \multirow{6}{*}{ Participant characteristics } & Months Since Diagnosis \\
\hline & Live Alone \\
\hline & Marital Status \\
\hline & Years of Education \\
\hline & Annual Gross Household Income \\
\hline & Ever Smoked \\
\hline \multirow{4}{*}{ Lymphedema Diagnosis } & Previous diagnosis of BCRL \\
\hline & Bioimpedance Resistance Ratio \\
\hline & Interlimb Volume Difference \\
\hline & Arm Circumference \\
\hline \multirow{7}{*}{ Signs/Symptoms } & Weight Gain Symptoms \\
\hline & DASH Score \\
\hline & Mean abduction range of motion affected side \\
\hline & Pain in Affected Breast \\
\hline & Pain in Affected Shoulder/Arm \\
\hline & Pain Interfering with Activity \\
\hline & Swelling Affected Shoulder/Arm \\
\hline
\end{tabular}

Table 6. Regression summary and coefficients

Peak $\mathrm{VO}_{2}$ Regression Summary

\begin{tabular}{cccccr}
\hline Model & \multirow{2}{*}{$\mathrm{R}$} & $\mathrm{R}^{2}$ & \multicolumn{3}{c}{ Change Statistics } \\
\cline { 5 - 6 } & & & $\mathrm{R}^{2}$ Change & F Change & Sig. F Change \\
Age & .397 & .158 & .158 & 23.050 & .000 \\
Age, BMI & .633 & .401 & .243 & 49.459 & .000 \\
Age, BMI, Meets exercise criteria & .684 & .467 & .067 & 15.131 & .000 \\
\hline
\end{tabular}

Coefficients

\begin{tabular}{|c|c|c|c|c|c|c|c|}
\hline & \multicolumn{2}{|c|}{$\begin{array}{l}\text { Unstandardized } \\
\text { Coefficients }\end{array}$} & \multirow{2}{*}{$\begin{array}{l}\text { Standardized } \\
\text { Coefficients }\end{array}$} & \multirow[t]{2}{*}{$\mathrm{t}$} & \multirow[t]{2}{*}{ Sig. } & \multicolumn{2}{|c|}{$\begin{array}{l}95 \% \text { Confidence Interval } \\
\text { for B }\end{array}$} \\
\hline & B & Std. Error & & & & $\begin{array}{l}\text { Lower } \\
\text { Bound }\end{array}$ & $\begin{array}{l}\text { Upper } \\
\text { Bound }\end{array}$ \\
\hline (Constant) & 52.460 & 2.988 & & 17.556 & $<0.001$ & 46.543 & 58.376 \\
\hline Age & -.236 & .040 & -.377 & -5.828 & $<0.001$ & -.316 & -.156 \\
\hline BMI & -.525 & .076 & -.449 & -6.872 & $<0.001$ & -.677 & -.374 \\
\hline $\begin{array}{l}\text { Meets exercise } \\
\text { criteria }\end{array}$ & 2.971 & .817 & .238 & 3.636 & $<0.001$ & 1.353 & 4.589 \\
\hline DASH (integer) & -.076 & .027 & -.185 & -2.837 & .005 & -.129 & -.023 \\
\hline
\end{tabular}

BMI: Body mass indexDASH: Disability of Arm, Shoulder and Hand questionnaire 


\section{Discussion}

Our findings support our hypothesis that breast cancer survivors have limited cardiorespiratory fitness compared to healthy age-matched women. Further, the women with BCRL demonstrated generally lower cardiorespiratory fitness $\left(\mathrm{VO}_{2}\right.$ peak) than the women without BCRL. The largest difference was found in the 40-49 year old age group, in which the women with lymphedema demonstrated $20 \%$ lower CR fitness than the women without lymphedema.Age, BMI, DASH scores, and meeting recommended exercise criteria explained an impressive $50 \%$ of the variance in $\mathrm{VO}_{2}$ peak.

This study identifies differences in $\mathrm{VO}_{2}$ peak in breast cancer survivors, both with and without lymphedema, and illuminates the need for attention to CR fitness during patient surveillance following breast cancer treatment. Patient education and treatment should include aerobic exercise prescription, particularly for those with BCRL. Physical activity guidelines should be included in discussions of survivorship, rehabilitation, and recovery following treatment for breast cancer. The Centers for Disease Control and Prevention (CDC) recommends participation in aerobic physical activity 30 minutes, five or more days per week (Centers for Disease Control and Prevention, 2010). According to the CDC, approximately $65 \%$ of adults in America met these exercise criteria in 2008. Only 45 of the 136 women in this study (33\%) met these guidelines. This is consistent with the findings of Irwin et al. (2003) that physical activity declines in breast cancer survivors.

Of the predictors found to contribute to the variance in $\mathrm{VO}_{2}$ peak, physical activity and $\mathrm{BMI}$ are modifiable. Four women demonstratedVO $\mathrm{V}_{2}$ peak of $40 \mathrm{ml} / \mathrm{kg} / \mathrm{min}$ or greater and each reported exercising 5 or more times per week. The addition of aerobic activity can improve physical fitness, and that, in conjunction with dietary modifications, can result in lowered BMI. Elevated BMI has been linked to increased risk of cardiovascular disease and cancer recurrence. Though not assessed in this study, elevated BMI prior to breast cancer treatment has also been implicated as a risk factor for BCRL (Soran et al., 2006).

Interestingly, although $\mathrm{VO}_{2}$ peak was statistically significantly different between the participants with BCRL and those without, neither group membership nor objective lymphedema outcome variables contributed to the variance in $\mathrm{VO}_{2}$ peak. This is intriguing in that volume changes in women with BCRL do not appear to be predictive of CR fitness, despite the fact that CR fitness is statistically significantly lower in the women with previously-diagnosed BCRL. Other between group differences therefore likely had a greater impact than did volume differences. Of the four predictors in the regression model (age, BMI, DASH score, and meeting recommended exercise criteria) only the DASH was statistically significantly different between groups. BMI was higher (though not statistically significantly so) in the BCRL group and was predictive of lower fitness. Future studies would be required to determine if variables not addressed in this study or factors associated with diagnosis of lymphedema, such as advice received or fear of exacerbation, might be more limiting than the physical impairments themselves.

There were four limitations of this study that merit discussion. First, the study's cross sectional design precludes determination of causality and a temporal relationship between cancer treatment and CR fitness. Second, group membership was determined by past-diagnosis of lymphedema by a health care provider. We were therefore unable to determine the accuracy of the diagnoses. Third, though the overall sample size was appropriate for the hypotheses tested, subgroup analysis by age group was likely underpowered, particularly for the under 40 and over 70 age groups. The numbers of women in these groups were too small to allow us to draw meaningful conclusions. And finally, the subjective nature of some of the predictor variables may have introduced a source of participant recall bias. To address these limitations in future research, a prospective study evaluating CR fitness prior to breast cancer surgery, and at regular intervals following surgery, would provide insight into the temporal sequence in declines in physical activity and CR fitness following treatment as well as the role of changing limb volume and other impairments.

\section{Conclusion}

Following breast cancer treatment, women report lower physical activity levels and demonstrate reduced aerobic capacity when compared to healthy age-matched norms. Women with BCRL have significantly lower peak $\mathrm{VO}_{2}$ than the women without BCRL. Age, BMI, DASH scores, and meeting the recommended exercise criteria explained $50 \%$ of the variance in peak $\mathrm{VO}_{2}$. Physical activity, cardiorespiratory fitness, and healthy BMI have been linked to improved health outcomes. It is essential that health care providers encourage and monitor physical activity and aerobic exercise with their patients following breast cancer treatment, with particular attention to women with or at risk for lymphedema who may have higher BMI and have greater reductions in physical activity and fitness. 


\section{References}

American Cancer Society. (2012). Breast Cancer Facts \& Figures 2011-2012. Atlanta: American Cancer Society, Inc.

American College of Sports Medicine. (2000). ACSM's guidelines for exercise testing and prescription(sixth ed.). Philadelphia, PA: Lippincott Williams \& Wilkins.

Beaton, D. E., Katz, J. N., Fossel, A. H., Wright, J. G., Tarasuk, V., \& Bombardier, C. (2001). Measuring the whole or the parts? Validity, reliability, and responsiveness of the Disabilities of the Arm, Shoulder and Hand outcome measure in different regions of the upper extremity. $J$ Hand Ther, 14, 128-146. http://dx.doi.org/10.1016/S0894-1130(01)80043-0

Calitchi, E., Kirova, Y. M., Otmezguine, Y., Feuilhade, F., Piedbois, Y., \& Le Bourgeois, J. P. (2001). Long-term results of neoadjuvant radiation therapy for breast cancer. Int $J$ Cancer, 96, 253-259. http://dx.doi.org/10.1002/ijc.1024

Centers for Disease Control and Prevention. State Indicator Report on Physical Activity, 2010. U.S. Department of Health and Human Services, Atlanta, GA: 2010.

Cheville, A. L., Troxel, A. B., Basford, J. R., \& Kornblith, A. B. (2008). Prevalence and treatment patterns of physical impairments in patients with metastatic breast cancer. J Clin Oncol, 26, 2621-2629. http://dx.doi.org/10.1200/JCO.2007.12.3075

Dawes, D. J., Meterissian, S., Goldberg, M., \& Mayo, N. E. (2008). Impact of lymphoedema on arm function and health-related quality of life in women following breast cancer surgery. $J$ Rehabil Med, 40, 651-658. http://dx.doi.org/10.2340/16501977-0232

Dorr, W., Bertmann, S., \& Herrmann, T. (2005). Radiation induced lung reactions in breast cancer therapy. Modulating factors and consequential effects. Strahlenther Onkol, 181, 567-573. http://www.springerlink.com/content/15688382wgr2g0n4/

Fehlauer, F., Tribius, S., Holler, U., Rades, D., Kuhlmey, A., Bajrovic, A., et al. (2003). Long-term radiation sequelae after breast-conserving therapy in women with early-stage breast cancer: an observational study using the LENT-SOMA scoring system. Int $J$ Radiat Oncol Biol Phys, 55, 651-658. http://dx.doi.org/10.1016/S0360-3016(02)04120-2

Gillette, E. L., Mahler, P. A., Powers, B. E., Gillette, S. M., \& Vujaskovic, Z. (1995). Late radiation injury to muscle and peripheral nerves. Int $J$ Radiat Oncol Biol Phys, 31, 1309-1318. http://dx.doi.org/10.1016/0360-3016(94)00422-H

Gummesson, C., Atroshi, I., \& Ekdahl, C. (2003). The disabilities of the arm, shoulder and hand (DASH) outcome questionnaire: longitudinal construct validity and measuring self-rated health change after surgery. BMC Musculoskelet Disord, 4, 11. http://dx.doi.org/10.1186/1471-2474-4-11

Irwin, M. L., Crumley, D., McTiernan, A., Bernstein, L., Baumgartner, R., Gilliland, F. D., et al. (2003). Physical activity levels before and after a diagnosis of breast carcinoma: the Health, Eating, Activity, and Lifestyle (HEAL) study. Cancer, 97, 1746-1757. http://dx.doi.org/10.1002/cncr.11227

Jones, L. W., Haykowsky, M., Peddle, C. J., Joy, A. A., Pituskin, E. N., Tkachuk, L. M., et al. (2007). Cardiovascular risk profile of patients with HER2/neu-positive breast cancer treated with anthracycline-taxane-containing adjuvant chemotherapy and/or trastuzumab. Cancer Epidemiol Biomarkers Prev, 16, 1026-1031. http://dx.doi.org/10.1158/1055-9965.EPI-06-0870

Kwan, M. L., Sternfeld, B., Ergas, I. J., Timperi, A. W., Roh, J. M., Hong, C. C., et al. (2012). Change in physical activity during active treatment in a prospective study of breast cancer survivors. Breast Cancer Res Treat, 131, 679-90. http://dx.doi.org/10.1007/s10549-011-1788-4

Kwan, W., Jackson, J., Weir, L. M., Dingee, C., McGregor, G., \& Olivotto, I. A. (2002). Chronic arm morbidity after curative breast cancer treatment: prevalence and impact on quality of life. $J$ Clin Oncol, 20, 4242-4248. http://dx.doi.org/10.1200/JCO.2002.09.018

Lakoski, S. G., Barlow, C. E., Farrell, S. W., Berry, J. D., Morrow, J. R., Jr., \& Haskell, W. L. (2011). Impact of body mass index, physical activity, and other clinical factors on cardiorespiratory fitness (from the Cooper Center longitudinal study). Am J Cardiol, 108, 34-39. http://dx.doi.org/10.1016/j.amjcard.2011.02.338 
McMillan, E. M., \& Newhouse, I. J. (2011). Exercise is an effective treatment modality for reducing cancer-related fatigue and improving physical capacity in cancer patients and survivors: a meta-analysis. Appl Physiol Nutr Metab.36, 892-903. http://dx.doi.org/10.1139/h11-082

McNeely, M. L., Campbell, K. L., Rowe, B. H., Klassen, T. P., Mackey, J. R., \& Courneya, K. S. (2006). Effects of exercise on breast cancer patients and survivors: a systematic review and meta-analysis. CMAJ, 175, 34-41. http://dx.doi.org/10.1503/cmaj.051073

Myers, J., \& Froelicher, V. F. (1993). Exercise testing. procedures and implementation. Cardiol Clin, 11, 199-213.

Norkin, C. C., \& White, D. J. (2003). Measurement of joint motion, a guide to goniometry (3rd ed.). Philadelphia, PA: FA Davis.

Ridner, S. H. (2005). Quality of life and a symptom cluster associated with breast cancer treatment-related lymphedema. Support Care Cancer, 13, 904-911. http://dx.doi.org/10.1007/s00520-005-0810-y

Rietman, J. S., Dijkstra, P. U., Hoekstra, H. J., Eisma, W. H., Szabo, B. G., Groothoff, J. W., et al. (2003). Late morbidity after treatment of breast cancer in relation to daily activities and quality of life: a systematic review. Eur J Surg Oncol, 29, 229-238. http://dx.doi.org/10.1053/ejso.2002.1403

Sander, A. P., Hajer, N. M., Hemenway, K., \& Miller, A. C. (2002). Upper-extremity volume measurements in women with lymphedema: a comparison of measurements obtained via water displacement with $\begin{array}{lllll}\text { geometrically determined } & \text { volume. Phys }\end{array}$ http://ptjournal.apta.org/content/82/12/1201.full.pdf + html

Sassen, B., Kok, G., Schaalma, H., Kiers, H., \& Vanhees, L. (2010). Cardiovascular risk profile: cross-sectional analysis of motivational determinants, physical fitness and physical activity. BMC Public Health, 10, 592. http://dx.doi.org/10.1186/1471-2458-10-592

Shapiro, C. L., \& Recht, A. (2001). Side effects of adjuvant treatment of breast cancer. N Engl J Med, 344, 1997-2008. http://dx.doi.org/10.1056/NEJM200106283442607

Smoot, B., Wong, J., Cooper, B., Wanek, L., Topp, K., Byl, N., et al. (2010). Upper extremity impairments in women with or without lymphedema following breast cancer treatment. J Cancer Surviv, 4, 167-178. http://dx.doi.org/10.1007/s11764-010-0118-x

Soran, A., D'Angelo, G., Begovic, M., Ardic, F., Harlak, A., Samuel Wieand, H., et al. (2006). Breast cancer-related lymphedema--what are the significant predictors and how they affect the severity of lymphedema? Breast J, 12, 536-543. http://dx.doi.org/10.1111/j.1524-4741.2006.00342.x

Taylor, D. L., Nichols, J. F., Pakiz, B., Bardwell, W. A., Flatt, S. W., \& Rock, C. L. (2010). Relationships between cardiorespiratory fitness, physical activity, and psychosocial variables in overweight and obese breast cancer survivors. Int J Behav Med, 17, 264-270. http://dx.doi.org/10.1007/s12529-010-9076-y 